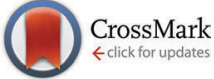

Cite this: J. Mater. Chem. C, 2015, 3, 3599

Received 30th October 2014 Accepted 19th February 2015

DOI: $10.1039 / c 4 t c 02476 a$

www.rsc.org/MaterialsC

\section{An ABA triblock copolymer strategy for intrinsically stretchable semiconductors $\dagger$}

\author{
Rui Peng, ${ }^{a}$ Bo Pang, ${ }^{a}$ Daqing $\mathrm{Hu}^{a}{ }^{a}$ Mengjie Chen, ${ }^{a}$ Guobing Zhang, ${ }^{a}$ \\ Xianghua Wang, ${ }^{a}$ Hongbo Lu, ${ }^{a b}$ Kilwon $\mathrm{ChO}^{\mathrm{C}}$ and Longzhen Qiu*ab
}

\begin{abstract}
A novel semiconductor-rubber-semiconductor (P3HT-PMA-P3HT) triblock copolymer has been designed and prepared according to the principle of thermoplastic elastomers. It behaves as a thermoplastic elastomer with a Young's modulus $(E)$ of $6 \mathrm{MPa}$ for an elongation at break of $140 \%$ and exhibits good electrical properties with a carrier mobility of $9 \times 10^{-4} \mathrm{~cm}^{2} \mathrm{~V}^{-1} \mathrm{~s}^{-1}$. This novel semiconductor may play an important role in low-cost and large-area stretchable electronics.
\end{abstract}

\section{Introduction}

Conjugated polymers have attracted enormous interest because of their potential applications in organic photovoltaics (OPVs), ${ }^{1-4}$ organic light-emitting diodes (OLEDs), ${ }^{5,6}$ and organic field-effect transistors (OFETs). ${ }^{7-9}$ Compared with their inorganic counterparts, conjugated polymers are much more flexible and suitable for fabricating revolutionary flexible electronic products which would be light in weight, bendable or foldable, and compatible to low-cost fabrication methods such as high-throughput printing processing. A large number of highly bendable polymer devices built on plastic or metal foils have been demonstrated with flexed radii as small as several millimeters. ${ }^{10,11}$ However, the rigid planar-conjugated backbones and highly crystallized states of conjugated polymers will inhibit the molecular motion and make the materials stiff and brittle,${ }^{12,13}$ which could lead to malfunction of the electronic devices under flexure. Furthermore, realization of stretchability in electronics is motivated by a wide range of applications including wearable electronics, smart skins, artificial organs, and integrated robotic sensors. ${ }^{14-16}$ Such devices require materials that can sustain large mechanical strain without the loss of their function. Various techniques have been developed to modify the mechanical properties of semiconductors, such as curved structures,${ }^{16}$ nanofibrillar networks ${ }^{10}$ and microcracks. ${ }^{13}$

\footnotetext{
${ }^{a}$ Key Lab of Special Display Technology, Ministry of Education, National Engineering Lab of Special Display Technology, State Key Lab of Advanced Display Technology, Academy of Opto-Electronic Technology, Hefei University of Technology, Hefei, 230009, China. E-mail: lzhqiu@hfut.edu.cn

${ }^{b}$ Key Lab of Advanced Functional Materials and Devices, Anhui Province, School of Chemical Engineering, Hefei University of Technology, Hefei, 230009, China

${ }^{c}$ Department of Chemical Engineering, Pohang University of Science and Technology, Pohang, 790-784, Korea

$\dagger$ Electronic supplementary information (ESI) available. See DOI: 10.1039/ c4tc02476a
}

In particular, Lipomi and coworkers systematically studied the effects of molecular structure including side chains,${ }^{17}$ segmentation on main chains ${ }^{18}$ and additives ${ }^{19}$ on the mechanical properties of conjugated polymers.

Conjugated block copolymers are promising molecular architectures because the physical and electrical properties of the copolymers can be fine-tuned either by changing the physical properties of the segments or by controlling the self-assembled nanostructures. Combining a conjugated polymer block with flexible insulating blocks has the potential to generate conjugated copolymers with excellent mechanical properties. There have been a large number of reports on the synthesis of block copolymers containing a conjugated segment. ${ }^{20-32}$ For example, Muller $e t$ al. $^{21}$ reported that diblock copolymers of polyethylene (PE) and P3HT display outstanding flexibility and toughness with elongations at break exceeding $600 \%$. However, the P3HT- $b$-PE copolymers show typical plastic characteristics and irreversible deformation under strain.

In this contribution, we conceptualize an unprecedented strategy to design and prepare semiconducting polymers with high elasticity according to the principle of ABA triblock copolymer thermoplastic elastomers (TPEs), such as polystyrene- $b$-polybutadiene- $b$-polystyrene (SBS) and polystyrene- $b$-polyisoprene$b$-polystyrene (SIS). The elasticity of such TPEs is derived from a two-phase nanostructure comprising hard polystyrene domains acting as physical cross-links in a rubbery matrix (Fig. 1a). Inspired by this system, we hypothesize that a class of novel semiconducting TPEs can be achieved by using rigid semiconducting polymer chains as hard segments and rubbery chains such as polyacrylate or poly(butadiene) as soft segments. However, charge transport in these semiconducting TPEs is challenging as the semiconducting phase disperses as a minor component in the dielectric matrix and can hardly form a conducting active channel. To solve this problem, a key feature of our process is controlling 


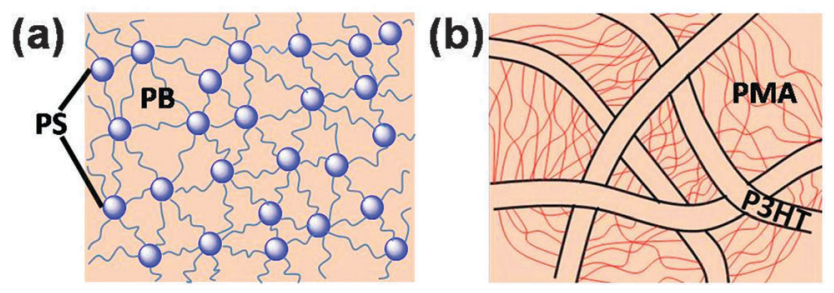

Fig. 1 Schematic illustration of (a) the structure of SBS, and (b) the structure of the P3HT-b-PMA- $b-\mathrm{P} 3 \mathrm{HT}$ triblock copolymer.

the semiconducting component to form a nanofibrillar network with ordered molecular stacking embedded in the insulating polymer matrix (Fig. 1b). Our previous results have shown that the embedded nanofibrillar networks permit the reduction of the semiconductor content to a level as low as $3 \mathrm{wt} \%$ without considerable degradation of the field-effect characteristics. ${ }^{33,34}$ If this architecture design indeed leads to the formation of semiconducting TPEs, it would provide a powerful platform for the preparation of a variety of semiconducting polymers with intrinsic stretchability.

\section{Experimental}

\subsection{Materials}

Diethyl meso-2,5-dibromoadipate and $N, N, N^{\prime}, N^{\prime \prime}, N^{\prime \prime}$-pentamethyldiethylenetriamine (PMDETA) were obtained from TCI Co. Ltd., Shanghai, China. Other chemicals used in this work were purchased from Sigma-Aldrich Chemical Company, Sinopharm Chemical Reagent Co. Ltd., China. Methyl acrylate (MA) was passed through a column of basic alumina to remove the 4-methoxyphenol stabilizer. Chemical reagents were purchased and used as received. Tetrahydrofuran (THF) and toluene were freshly distilled over sodium wire under nitrogen prior to use.

\subsection{Synthesis of PMA block (Br-PMA-Br) (1)}

An oven-dried $100 \mathrm{ml}$ flask was cooled under nitrogen and charged with diethyl meso-2,5-dibromoadipate (0.58 g, $1.61 \mathrm{mmol})$, methyl acrylate $(10 \mathrm{~g}, 116.3 \mathrm{mmol})$, toluene $(6 \mathrm{ml})$, PMDETA $(0.28 \mathrm{~g}$, $1.61 \mathrm{mmol}$ ) and a stir bar. The reaction mixture was purged with nitrogen for $30 \mathrm{~min}$ in an ice-bath, and $\mathrm{CuBr}(0.23 \mathrm{~g}, 1.61 \mathrm{mmol})$ was added. The flask was sealed with a rubber septum and warmed to room temperature. The reaction mixture was placed in an oil bath at $75{ }^{\circ} \mathrm{C}$. After stirring the mixture for $4 \mathrm{~h}$, the reaction was cooled to room temperature. The mixture was added to THF and passed through a neutral column (eluent $=\mathrm{THF}$ ) to remove the residual catalyst. The solution was concentrated using a rotary evaporator. Afterward, it was precipitated into cold methanol to remove the residual monomer and other impurities. The polymer was dried under vacuum at $50{ }^{\circ} \mathrm{C}$ for $24 \mathrm{~h}(8.6 \mathrm{~g}, 86 \%$ yield $)$. Data for PMA ${ }_{128}:$ GPC: $\overline{M_{\mathrm{n}}}=11.2 \mathrm{kDa}, \mathrm{PDI}=1.08 .{ }^{1} \mathrm{H}$ NMR (Fig. S1 in $\mathrm{ESI}, \dagger \mathrm{CDCl}_{3}, \mathrm{ppm}$ ): $\delta 4.25$ (m, $\mathrm{CH}-\mathrm{Br}$ ), 4.13 (broad, $\mathrm{OCH}_{2} \mathrm{CH}_{3}$ ), 3.76 $\left(\mathrm{m}, \mathrm{CHBrCOOCH}_{3}\right), 3.69\left(\mathrm{~s}, \mathrm{CH}_{3} \mathrm{O}\right), 2.3$ (broad, $\mathrm{CH}$ of polymer backbone), 1.94, 1.67, 1.51 (m, $\mathrm{CH}_{2}$ of polymer backbone), 1.25 (t, $\mathrm{OCH}_{2} \mathrm{CH}_{3}$ ). FT-IR: $\nu_{\mathrm{C}=\mathrm{O}}=1750 \mathrm{~cm}^{-1}$.

\subsection{Synthesis of PMA block $\left(\mathrm{N}_{3}-\mathrm{PMA}-\mathrm{N}_{3}\right)(2)$}

A round-bottomed glass flask $(100 \mathrm{ml})$ with a magnetic bar was charged with $\mathrm{Br}-\mathrm{PMA}-\mathrm{Br}\left(\overline{M_{\mathrm{n}}}=11.2 \mathrm{kDa}, 5 \mathrm{~g}, 0.45 \mathrm{mmol}\right)$, $\mathrm{NaN}_{3}(0.29 \mathrm{~g}, 4.5 \mathrm{mmol})$ and DMF $(40 \mathrm{ml})$. The resulting solution was stirred at room temperature for $24 \mathrm{~h}$. After adding $\mathrm{CH}_{2} \mathrm{Cl}_{2}(200 \mathrm{ml})$ and water $(200 \mathrm{ml})$, the organic phase was separated and washed with water $(30 \mathrm{ml} \times 4)$, and then dried using $\mathrm{Na}_{2} \mathrm{SO}_{4}$. The solution was concentrated by a rotary evaporator. Afterward, it was precipitated into cold methanol to remove the residual DMF. The polymer was dried under vacuum at $50{ }^{\circ} \mathrm{C}$ for $24 \mathrm{~h}(4 \mathrm{~g}, 80 \%$ yield $)$. GPC: $\overline{M_{\mathrm{n}}}=11.2 \mathrm{kDa}$, $\mathrm{PDI}=1.08 .{ }^{1} \mathrm{H}$ NMR (Fig. S2 in ESI, $\left.\dagger \mathrm{CDCl}_{3}, \mathrm{ppm}\right): \delta 4.13$ (broad, $\left.\mathrm{OCH}_{2} \mathrm{CH}_{3}\right), 3.93\left(\mathrm{CH}_{2}-\mathrm{N}_{3}\right), 3.76\left(\mathrm{~m}, \mathrm{CHN}_{3} \mathrm{COOCH}_{3}\right), 3.69$ (s, $\mathrm{CH}_{3} \mathrm{O}$ ), 3.66 (broad, $\mathrm{CH}_{3}$ of polymer backbone), 2.3 (broad, $\mathrm{CH}$ of polymer backbone), 1.94, 1.67, 1.51 (m, $\mathrm{CH}_{2}$ of polymer backbone), $1.25\left(\mathrm{t}, \mathrm{OCH}_{2} \mathrm{CH}_{3}\right)$. FT-IR: $\nu_{\mathrm{C}=\mathrm{O}}=1750 \mathrm{~cm}^{-1} \cdot \nu_{\mathrm{N} 3}=$ $2100 \mathrm{~cm}^{-1}$.

\subsection{Synthesis of ethynyl-terminated P3HT (P3HT-ethynyl) (3)}

According to the literature, ${ }^{20,23}$ in a typical experiment, an oven-dried two-necked glass flask $(200 \mathrm{ml})$ was cooled under nitrogen and charged with 2,5-dibromo-3-hexylthiophene (4.36 g, $13.4 \mathrm{mmol})$, anhydrous THF ( $40 \mathrm{ml})$ and a magnetic stir bar. After adding tert-butylmagnesium chloride $(13.4 \mathrm{ml}, 1 \mathrm{M}$ solution in $\mathrm{THF}$ ), the reaction mixture was stirred at room temperature for $2 \mathrm{~h}$. Subsequently, the mixture was diluted to $130 \mathrm{ml}$ with anhydrous THF and $\mathrm{Ni}(\mathrm{dppp}) \mathrm{Cl}_{2}(0.069 \mathrm{~g}, 0.127 \mathrm{mmol})$ was added. After $30 \mathrm{~min}$, ethynylmagnesium bromide $(2.5 \mathrm{ml}, 0.5 \mathrm{M}$ solution in THF) was added. After an additional $30 \mathrm{~min}$, methanol was poured into the glass flask, which caused a dark-pure solid to precipitate. The desired P3HT was purified by a series of precipitations and dried under vacuum at room temperature ( $1.7 \mathrm{~g}, 40 \%$ yield). GPC: $\overline{M_{\mathrm{n}}}=5.6 \mathrm{kDa}, \mathrm{PDI}=1.02 .{ }^{1} \mathrm{H}$ NMR (Fig. S3 in ESI, $\dagger \mathrm{CDCl}_{3}, \mathrm{ppm}$ ): $\delta 6.98$ (s, $\mathrm{CH}$ of the thiophene ring), 3.52 (s, $\mathrm{CH}$ of terminal ethynyl), $2.80\left(\mathrm{t}, \mathrm{CH}_{2} \mathrm{CH}_{2} \mathrm{CH}_{2} \mathrm{CH}_{2} \mathrm{CH}_{2} \mathrm{CH}_{3}\right), 1.71\left(\mathrm{~m}, \mathrm{CH}_{2} \mathrm{CH}_{2} \mathrm{CH}_{2} \mathrm{CH}_{2^{-}}\right.$ $\left.\mathrm{CH}_{2} \mathrm{CH}_{3}\right), 1.50-1.30\left(\mathrm{~m}, \mathrm{CH}_{2} \mathrm{CH}_{2} \mathrm{CH}_{2} \mathrm{CH}_{2} \mathrm{CH}_{2} \mathrm{CH}_{3}\right), 0.9$ (t, $\mathrm{CH}_{2} \mathrm{CH}_{2}^{-}$ $\left.\mathrm{CH}_{2} \mathrm{CH}_{2} \mathrm{CH}_{2} \mathrm{CH}_{3}\right)$.

\subsection{Synthesis of P3HT-PMA-P3HT triblock copolymer (4)}

$\mathrm{N}_{3}-$ PMA- $\mathrm{N}_{3}\left(\overline{M_{\mathrm{n}}}=11.2 \mathrm{kDa}, 0.5 \mathrm{~g}, 0.0455 \mathrm{mmol}\right)$, P3HT-ethynyl $\left(\overline{M_{\mathrm{n}}}=5.6 \mathrm{kDa}, 0.51 \mathrm{~g}, 0.0910 \mathrm{mmol}\right)$ and PMDETA $(0.016 \mathrm{~g}$, $0.0910 \mathrm{mmol}$ ) were dissolved in anhydrous THF. The resulting solution was purged with nitrogen for $40 \mathrm{~min}$ in an ice-bath, subsequently $\mathrm{CuBr}(0.014 \mathrm{~g}, 0.0910 \mathrm{mmol})$ was added under nitrogen. The reaction mixture was placed in an oil bath at $50{ }^{\circ} \mathrm{C}$ for 3 days and taken out of the oil bath to cool to room temperature. The solution was diluted with THF and passed through a neutral column (eluent $=\mathrm{THF}$ ) to remove residual catalyst, then concentrated using a rotary evaporator to afford the crude product. The desired polymers were confirmed by $\mathrm{H}$ NMR and GPC. GPC: $\overline{M_{\mathrm{n}}}=19 \mathrm{kDa}$, PDI $=1.12 .{ }^{1} \mathrm{H}$ NMR $\left(\mathrm{CDCl}_{3}, \mathrm{ppm}\right): 7.43$ (s, $\mathrm{CH}$ of triazole rings), 6.98 (s, $\mathrm{CH}$ of the thiophene ring), 4.13 (broad, $\mathrm{OCH}_{2} \mathrm{CH}_{3}$ ), 3.66 (broad, $\mathrm{OCH}_{3}$ ), 2.80 (t, $\mathrm{CH}_{2} \mathrm{CH}_{2} \mathrm{CH}_{2} \mathrm{CH}_{2} \mathrm{CH}_{2} \mathrm{CH}_{3}$ ), 2.3 (broad, $\mathrm{CH}$ of poly(methyl acrylate) block), 1.94 (broad, $\mathrm{CH}_{2} \mathrm{CH}$ of poly(methyl acrylate) block), 
$1.71\left(\mathrm{~m}, \quad \mathrm{CH}_{2} \mathrm{CH}_{2} \mathrm{CH}_{2} \mathrm{CH}_{2} \mathrm{CH}_{2} \mathrm{CH}_{3}\right), \quad 1.50-1.30 \quad\left(\mathrm{~m}, \mathrm{CH}_{2} \mathrm{CH}_{2}-\right.$ $\mathrm{CH}_{2} \mathrm{CH}_{2} \mathrm{CH}_{2} \mathrm{CH}_{3}$ ).

\subsection{Fabrication and characterization of field-effect transistors}

Heavily n-doped $\mathrm{Si}$ wafer with $300 \mathrm{~nm}$ thermally grown $\mathrm{SiO}_{2}$ surface layer (capacitance of $10.8 \mathrm{nF} \mathrm{cm}^{-2}$ ) was employed as the substrate for the fabrication of OFETs. The n-type Si wafer serves as the common gate electrode and the $\mathrm{SiO}_{2}$ layer acts as the gate dielectric. Prior to the modification of the $\mathrm{SiO}_{2}$ layer with octadecyltrichlorosilane (ODTS), the wafer was cleaned in piranha solution ( $70 \mathrm{vol} \% \mathrm{H}_{2} \mathrm{SO}_{4}+30 \mathrm{vol} \% \mathrm{H}_{2} \mathrm{O}_{2}$ ) for $30 \mathrm{~min}$ at $100{ }^{\circ} \mathrm{C}$ and washed with copious amounts of distilled water. The ODTS self-assembled monolayers (SAMs) were prepared by dipping the cleaned wafer into a $0.1 \mathrm{M}$ toluene solution of ODTS for $2 \mathrm{~h}$. A chloroform solution containing the semiconductor polymer was dropped onto the ODTS-SAM modified wafer and spin-coated. The polymer films were subsequently annealed (100-200 $\left.{ }^{\circ} \mathrm{C}\right)$ in nitrogen. Then $\mathrm{Au}$ source-drain electrodes were prepared by thermal evaporation. The OFET devices had a channel length $(L)$ of $100 \mu \mathrm{m}$ and channel width $(W)$ of $1 \mathrm{~mm}$. The electrical characteristics of the OFET devices were measured in accumulation mode using a Keithley 2400 instrument under ambient conditions. The mobility values were obtained by using the following equation used at saturation regime: $I_{\mathrm{d}}=(W / 2 L) C_{\mathrm{i}} \mu\left(V_{\mathrm{g}}-V_{\mathrm{th}}\right)^{2}$, where $W / L$ is the channel width/length, $I_{\mathrm{d}}$ is the drain current in the saturated regime, $C_{\mathrm{i}}$ is the capacitance of the $\mathrm{SiO}_{2}$ gate dielectric, and $V_{\text {th }}$ is the threshold voltage.

\subsection{Instrumentation}

Nuclear magnetic resonance (NMR) spectra were recorded on a Mercury plus $600 \mathrm{MHz}$ machine. Gel permeation chromatography (GPC) analyses were performed on a Waters Series 1525 gel coupled with a UV-vis detector using tetrahydrofuran as eluent with polystyrene as standard. Polystyrene standards in the range of 4100 to $278000 \mathrm{~g} \mathrm{~mol}^{-1}$ were used to calibrate the GPC. The flow rate for

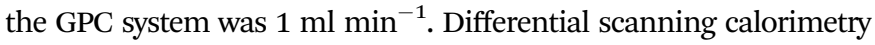
(DSC) was performed on a TA instrument Q2000 in a nitrogen atmosphere. The sample (about $3.0 \mathrm{mg}$ in weight) was first heated to $250{ }^{\circ} \mathrm{C}$ and held for $5 \mathrm{~min}$ to remove thermal history, followed by a cooling rate of $10{ }^{\circ} \mathrm{C} \mathrm{min}^{-1}$ to $-40{ }^{\circ} \mathrm{C}$ and then a heating rate of $10{ }^{\circ} \mathrm{C} \min ^{-1}$ to $250{ }^{\circ} \mathrm{C}$ in all cases. UV-vis absorption spectra were recorded on a Perkin Elmer model $\lambda 20 \mathrm{UV}$-vis spectrophotometer. IR spectra were recorded using a Thermo Nicolet Spectrum Nicolet 67 system using $\mathrm{KBr}$ pellets. Atomic force microscopy (AFM) images were obtained using a Veeco Multimode V instrument. Tensile tests were performed at room temperature on rectangular samples $(20 \mathrm{~mm} \times 5 \mathrm{~mm} \times 1 \mathrm{~mm})$ using a CMT4000 tensile machine, with a strain rate $2 \mathrm{~mm} \mathrm{~min}^{-1}$.

\section{Results and discussion}

\subsection{Synthesis and characterization}

The synthesis route for the triblock copolymers is illustrated in Scheme 1. A novel semiconductor-rubber-semiconductor triblock copolymer, poly(3-hexylthiophene)-poly(methyl acrylate)poly(3-hexylthiophene) (P3HT-PMA-P3HT), was synthesized via the "click" reaction of two ethynyl-terminated P3HT (P3HT$\mathrm{C} \equiv \mathrm{CH}$ ) chains and an $\alpha, \omega$-diazido-terminated poly(methyl acrylate) $\left(\mathrm{N}_{3}-\mathrm{PMA}-\mathrm{N}_{3}\right)$. Well-fined $\mathrm{N}_{3}-\mathrm{PMA}-\mathrm{N}_{3}$ was synthesized via $\mathrm{Cu}$-mediated atom transfer radical polymerization of methyl acrylate initiated by diethyl meso-2,5-dibromoadipate, followed by displacement of the bromide end-group with azides using $\mathrm{NaN}_{3}$ in DMF at room temperature. Monomodal P3HT-C $\equiv \mathrm{CH}$ was prepared via a Ni-catalyzed Grignard metathesis (GRIM) polymerization and purified according to literature procedures. ${ }^{35} \mathrm{~N}_{3}-\mathrm{PMA}-\mathrm{N}_{3}$

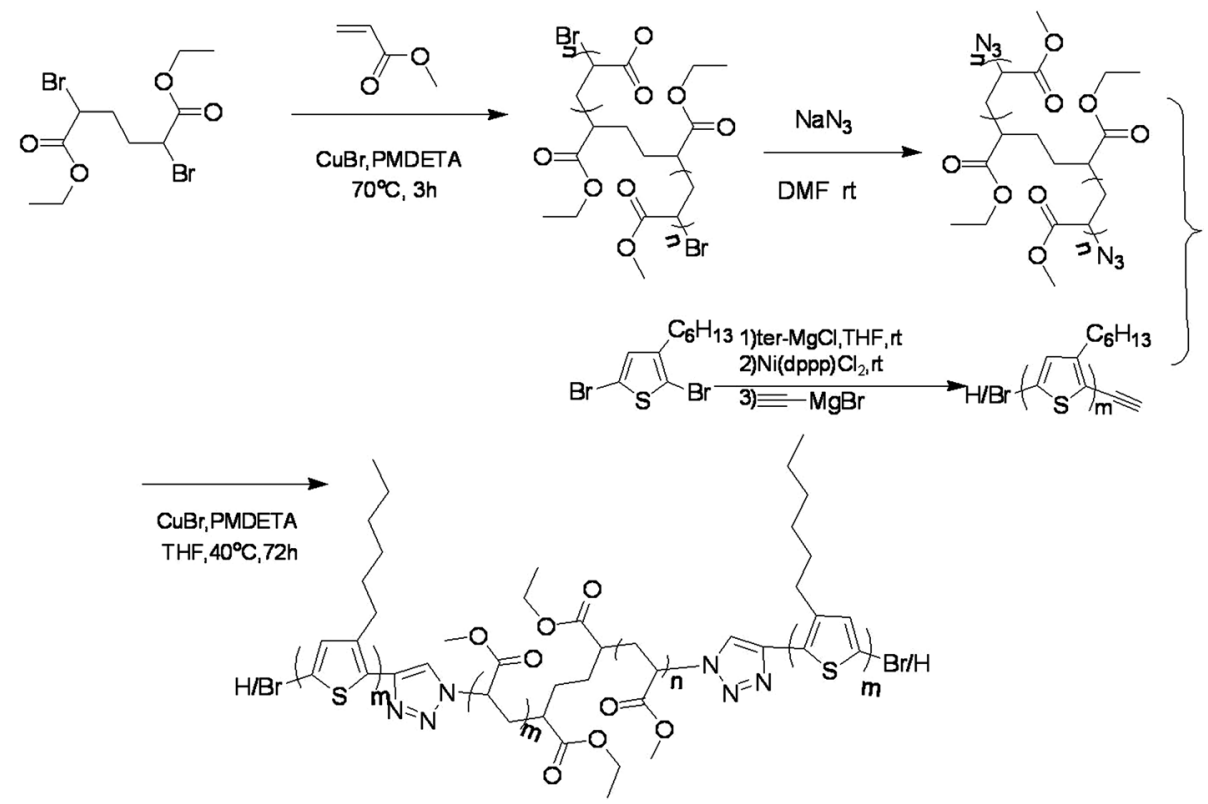

Scheme 1 Synthesis route for P3HT-b-PMA-b-P3HT triblock copolymer. 


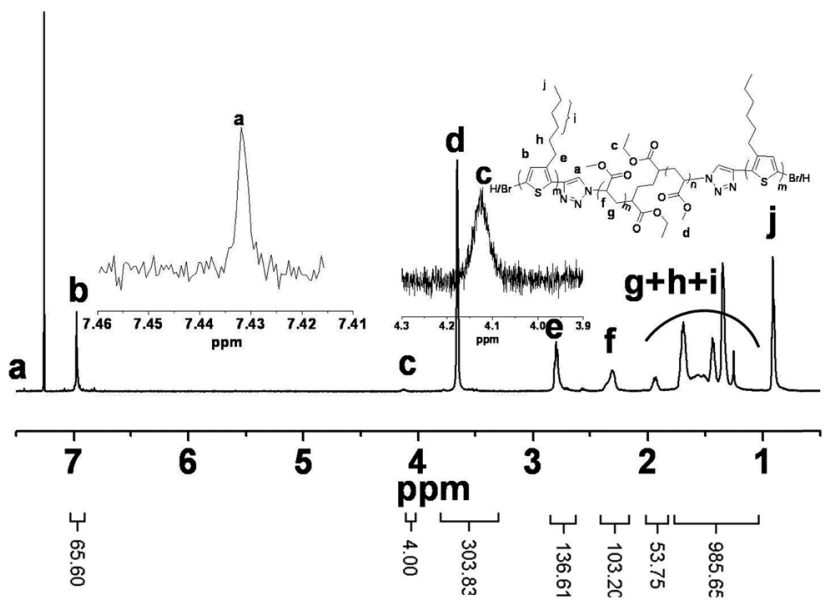

Fig. 2 The ${ }^{1} \mathrm{H}$ NMR spectrum of P3HT- $b$-PMA- $b-\mathrm{P} 3 \mathrm{HT}$ triblock copolymer (P3).

was reacted with 2 equiv. of P3HT-C $\equiv \mathrm{CH}$ using $N, N, N^{\prime}, N^{\prime \prime}, N^{\prime \prime}$ pentamethyldiethylenetriamine (PMDETA)/CuBr as the catalyst system at $40{ }^{\circ} \mathrm{C}$ in tetrahydrofuran (THF). After filtering the resulting reaction mixture through neutral alumina to remove the catalyst, the crude P3HT-PMA-P3HT triblock copolymers were obtained by precipitating the reaction mixtures in methanol.

As shown in Fig. 2, ${ }^{1} \mathrm{H}-\mathrm{NMR}$ spectroscopy was used to determine the structures of the triblock copolymers. The absence of the starting $\mathrm{P} 3 \mathrm{HT}-\mathrm{C} \equiv \mathrm{CH}$ and $\mathrm{N}_{3}-\mathrm{PMA}^{-\mathrm{N}_{3}}$ was confirmed by the disappearance of both resonances corresponding to the alkynyl groups at $\delta=3.52 \mathrm{ppm}$ and the azide moiety at $\delta=3.9 \mathrm{ppm}$. The formation of the triazole rings was confirmed by the presence of a new resonance at $\delta=7.43 \mathrm{ppm}^{20}$ and the disappearance of the diagnostic $\nu_{\mathrm{N} 3}$ IR signal (Fig. S4 in ESI $\dagger$ ). Moreover, after purification via gel permeation chromatography (GPC), a triblock copolymer composed of two rodlike $5600 \mathrm{~g} \mathrm{~mol}^{-1} \mathrm{rr}-\mathrm{P} 3 \mathrm{HT}$ chains covalently linked to a $11200 \mathrm{~g} \mathrm{~mol}^{-1}$ PMA coil polymer with an overall number-average molecular weight of $19000 \mathrm{~g} \mathrm{~mol}^{-1}$ was obtained (see Fig. 3a and b). Notably, a small shoulder appeared in the GPC trace of the crude triblock copolymers since P3HT with alkyne end groups could not reach 100\% conversion. $^{36,37}$ However, the limited portion of P3HT homopolymer in the triblock copolymer has no influence on the electrical and mechanical performance, because P3HT can self-assemble into well-ordered nanowires acting as charge transport channels.
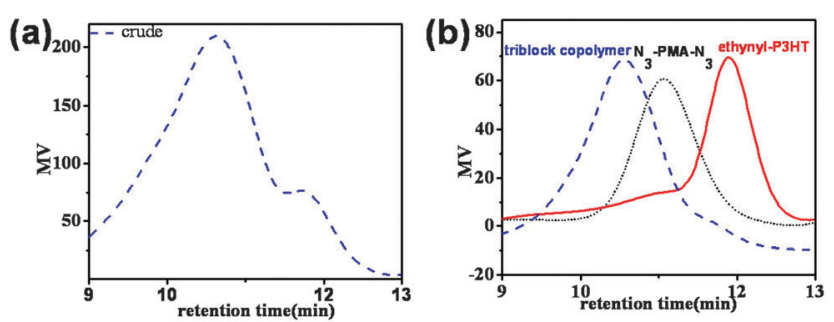

Fig. 3 Representative GPC trace of the crude product (a, blue line) and highly purified triblock copolymers (b, blue line), poly(methyl acrylate) homopolymer (b, black line) and P3HT homopolymer (b, red line).
The chemical compositions of the four triblock copolymers derived from P3HT and PMA segments of different molecular weights are summarized in Table 1.

\subsection{Optical properties}

UV-visible absorbance spectra, which were referenced to the extended triblock and collapsed triblock, were collected in dilute chloroform solution and solid state film forms. In Fig. 4 (red line), the triblock exhibited a broad absorption peak centered at $455 \mathrm{~nm}$, which corresponded to the $\pi-\pi^{*}$ electronic transition of the triblock copolymer in solution. This phenomenon resembled the characteristic of highly rr-P3HT. The black line represents the collapsed triblock, a broad $\pi-\pi^{*}$ electronic transition band was evident with a peak centered at $518 \mathrm{~nm}$ and two additional vibronic structures at $548 \mathrm{~nm}$ and $605 \mathrm{~nm}$ which were interpreted as the coupling of the $\mathrm{C}=\mathrm{C}$ double bond symmetric stretch and the $\pi-\pi^{*}$ electronic transition. The large red shift (about $70 \mathrm{~nm}$ ) between solution and solid state films indicates the presence of strong intermolecular interactions and the planarization effect of the conjugated polymer backbone. The results suggest that intermolecular interactions are relatively strong in favor of the mobility.

\subsection{Thermal and mechanical properties}

The thermal behavior of the P3HT- $b$-PMA- $b$-P3HT triblock copolymer was investigated by differential scanning calorimetry (DSC) (Fig. 5). The DSC trace of P3HT- $b$-PMA- $b$-P3HT triblock copolymer was typical of an immiscible system. The result was in agreement with the obvious difference in solubility between P3HT $\left(13.1(\mathrm{MPa})^{1 / 2}\right)^{38}$ and PMA (20.7 $\left.(\mathrm{MPa})^{1 / 2}\right){ }^{39}$ which provides a strong driving force for phase separation. It showed a glass transition at $2{ }^{\circ} \mathrm{C}$ corresponding to the $T_{\mathrm{g}}$ of the PMA phase and an endotherm peak at $200{ }^{\circ} \mathrm{C}$ corresponding to $T_{\mathrm{m}}$ of the P3HT phase. The $T_{\mathrm{g}}$ of PMA segments and the $T_{\mathrm{m}}$ of P3HT segments in triblock copolymer were lower than those of PMA $\left(10{ }^{\circ} \mathrm{C}\right)^{40}$ and P3HT $\left(215.6{ }^{\circ} \mathrm{C}\right)^{41}$ homopolymers because of their relatively low molecular weight.

Although the starting $\mathrm{N}_{3}-\mathrm{PMA}-\mathrm{N}_{3}$ is viscous and P3HT$\mathrm{C} \equiv \mathrm{CH}$ is brittle at room temperature, the P3HT- $b$-PMA- $b$ P3HT triblock copolymers have excellent mechanical properties. The film of $\mathbf{P 4}$ can be elastically deformed as displayed in the insert of Fig. 6. The strain-stress curve indicates a Young's modulus $(E)$ of $6 \mathrm{MPa}$, an elongation at break $(\varepsilon)$ of $140 \%$ and a true stress at break $\left[\sigma_{\mathrm{t}}=\sigma(1+\varepsilon / 100)\right]$ (here, $\sigma$ is the maximum stress at break) of 1.4 MPa. Compared with $E$ of $28 \mathrm{MPa}, \varepsilon$ of $13 \%$ and $\sigma_{\mathrm{t}}$ of $4 \mathrm{MPa}$ for the P3HT homopolymer reported in the literature, ${ }^{21}$ the modulus became lower and the elongation became larger, which are typical characteristics of a plastic-torubber transition. It should be noted that the mechanical properties of P3HT are highly dependent on the measuring method. For instance, O'Connor ${ }^{12}$ and Lipomi ${ }^{42}$ reported the modulus of P3HT films was $0.25 \mathrm{GPa}$ and $0.92 \mathrm{GPa}$ using a buckling-based metrology. The reason may be that the bucklingbased technique measured the in-plane elastic modulus, and the anisotropic microstructure of the films may lead to an anisotropic elastic modulus. For comparison, we used the data of bulk 
Table 1 Compositions of P3HT- $b$-PMA- $b-\mathrm{P} 3 \mathrm{HT}$

\begin{tabular}{|c|c|c|c|c|c|c|c|}
\hline Polymer & P3HT block (NMR) & PMA block (NMR) & P3HT (wt\%) & P3HT block (GPC) & PMA block (GPC) & $\overline{M_{\mathrm{n}}}(\mathrm{GPC})$ & PDI (GPC) \\
\hline $\mathrm{P}_{3} \mathrm{HT}_{1}$ & 3800 & - & 100 & 5200 & - & - & 1.04 \\
\hline $\mathrm{P}_{3} \mathrm{HT}_{2}$ & 6600 & - & 100 & 5600 & - & - & 1.02 \\
\hline P1 & 3800 & 11000 & 41 & 5200 & 11200 & 19000 & $1.29 / 1.12^{a}$ \\
\hline P2 & 3800 & 24000 & 24 & 5200 & 14000 & 26000 & 1.38 \\
\hline P3 & 6600 & 11000 & 55 & 5600 & 11200 & 16000 & 1.51 \\
\hline P4 & 6600 & 24000 & 35 & 5600 & 14000 & 27000 & 1.64 \\
\hline
\end{tabular}

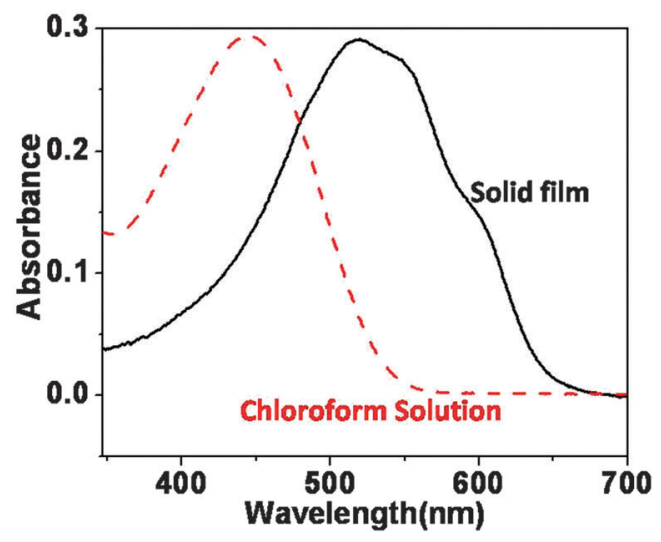

Fig. 4 UV-vis absorption spectra of P3HT-b-PMA- $b$-P3HT in chloroform solution and in thin film form.

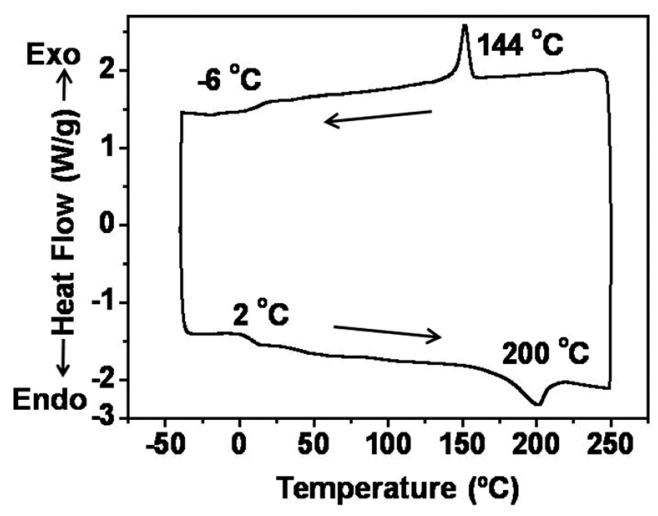

Fig. 5 The DSC trace of P3HT-PMA-P3HT triblock copolymer.

samples obtained from a similar measurement technique. Furthermore, the mechanical properties of our triblock copolymer could be improved by increasing the molecular weight of the soft PMA block.

\subsection{The film morphologies and microstructure}

Film morphology and crystallinity play important roles in OFET device performance. Atomic force microscopy (AFM) was applied to investigate the morphology of $\mathbf{P 4}$ films annealed at different temperatures for $15 \mathrm{~min}$ (Fig. 7). The AFM phase image of an as-prepared film without any thermal annealing shows a granular phase pattern. As the annealing temperature increased, the granular domains are elongated. When annealed

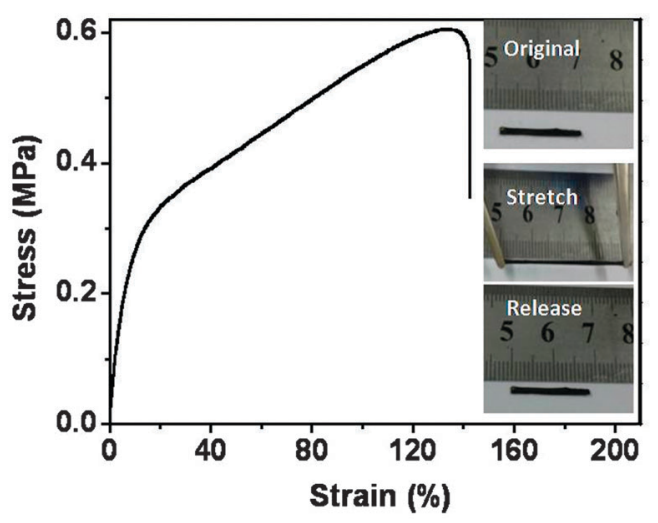

Fig. 6 The strain-stress profile of P3HT-PMA-P3HT triblock copolymer.
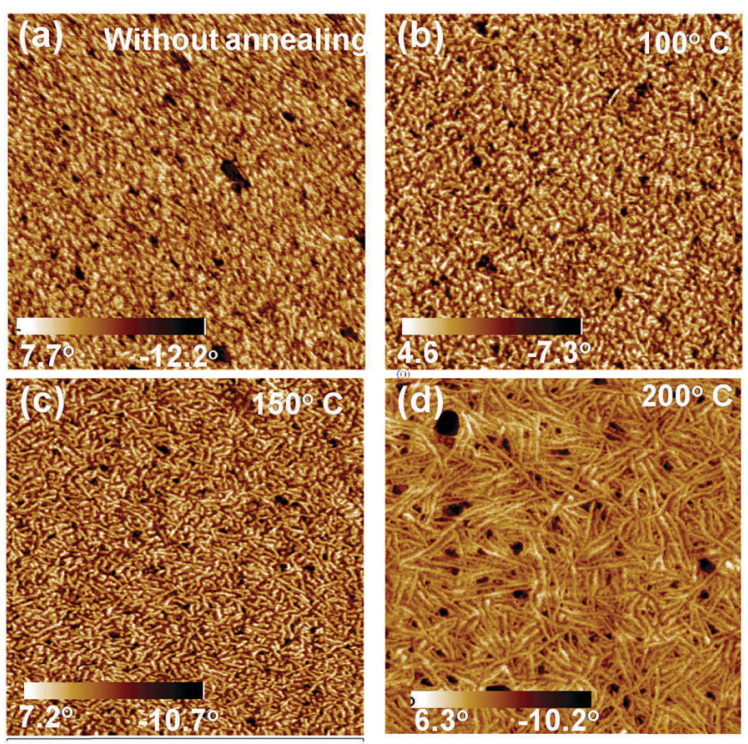

Fig. 7 AFM topography images of P3HT-PMA-P3HT at different annealing temperatures.

at $200{ }^{\circ} \mathrm{C}$, the AFM images showed clear evidence of nanofibrillar structures with lengths of several hundred nanometers and widths of about $10 \mathrm{~nm}$. Considering the PMA is in a rubbery state, the nanofibrillar structures can be attributed as a result of $\pi-\pi$ stacking of P3HT segments. The P3HT nanofibers with high aspect ratios can keep the connectivity of the semiconducting layers in the block copolymer films and thus play a significant role in achieving effective charge transport. ${ }^{43}$ 

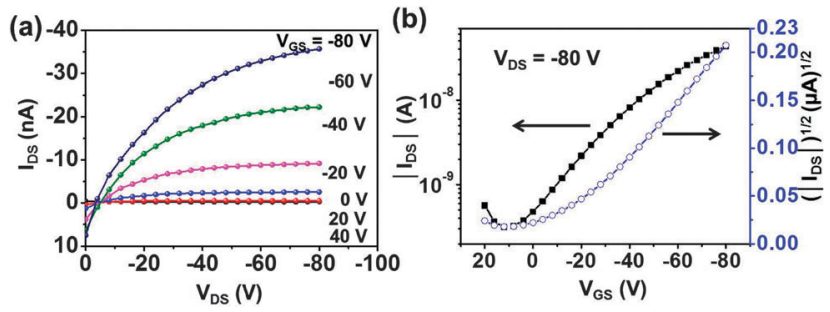

Fig. 8 Field-effect characteristics of top contact OFETs based on P4 (a) output and (b) transfer.

\subsection{OFET characterization}

OFETs device with bottom-gate and top-contact geometry were used to investigate the field-effect mobility of P3HT- $b$-PMA- $b$ P3HT triblock copolymers. Fig. 8 shows the typical field-effect transistor characteristics of $\mathbf{P 4}$ measured in accumulation mode under ambient conditions. The devices were found to be well-behaved p-type transistors with a clear linear regime at small source-drain voltages and a saturation regime at $V_{\mathrm{DS}}$ values higher than the gate voltage. Table 2 summarizes the device parameters for all of the polymers. The homo P3HT films with molecular weights of 3.8 and $6.6 \mathrm{~kg} \mathrm{~mol}^{-1}$ (NMR) showed carrier mobilities of $1.7 \times 10^{-4}$ and $2.4 \times 10^{-4} \mathrm{~cm}^{2} \mathrm{~V}^{-1} \mathrm{~s}^{-1}$

Table 2 Summary of all field-effect mobilities of $\mathrm{rr}-\mathrm{P} 3 \mathrm{HT}$ and the triblock copolymers

\begin{tabular}{llllc}
\hline Polymer & $\begin{array}{l}\text { Mobility } \\
\left(\mathrm{cm}^{2} \mathrm{~V}^{-1} \mathrm{~s}^{-1}\right)\end{array}$ & $\begin{array}{l}\text { Max mobility } \\
\left(\mathrm{cm}^{2} \mathrm{~V}^{-1} \mathrm{~s}^{-1}\right)\end{array}$ & $\begin{array}{l}\text { On/off } \\
\text { ratio }\end{array}$ & $\begin{array}{l}\text { Threshold } \\
\text { voltage }\end{array}$ \\
\hline P3HT $_{1}$ & $1.5 \times 10^{-4}$ & $4.2 \times 10^{-4}$ & 33 & 17.6 \\
P3HT $_{2}$ & $2.4 \times 10^{-4}$ & $4.5 \times 10^{-4}$ & 207 & 17.3 \\
P1 & $3.5 \times 10^{-4}$ & $4.3 \times 10^{-4}$ & 166 & 4.9 \\
P2 & $9.9 \times 10^{-5}$ & $1.1 \times 10^{-4}$ & 175 & 7.2 \\
P3 & $3.0 \times 10^{-4}$ & $9.0 \times 10^{-4}$ & 246 & -10.7 \\
P4 & $1.7 \times 10^{-4}$ & $2.1 \times 10^{-4}$ & 666 & -8.6
\end{tabular}

(Fig. S5 in ESI $\dagger$ ), respectively. The poor mobilities observed in our work are attributed to the low molecular weight of P3HT and are comparable with those of P3HT with similar molecular weight reported in literature. ${ }^{37}$ The field-effect performances of triblock copolymers are highly dependent on the content of P3HT segments. P1 (41\% P3HT) and P3 (55\% P3HT) with relatively high contents of $\mathrm{P} 3 \mathrm{HT}$ displayed enhanced mobilities of $3.5 \times 10^{-4}$ and $3.0 \times 10^{-4} \mathrm{~cm}^{2} \mathrm{~V}^{-1} \mathrm{~s}^{-1}$, respectively, compared to their P3HT homopolymers. The enhancement of charge transport properties was also reported in poly(3-hexylthiophene)- $b$-polystyrene diblock copolymers and was ascribed to the highly crystalline, ordered P3HT domains in the copolymer films. ${ }^{43}$ The mobility of the triblock copolymers decreased with higher PMA content because the PMA segment is an insulator. The maximum carrier mobility was $9 \times 10^{-4} \mathrm{~cm}^{2} \mathrm{~V}^{-1} \mathrm{~s}^{-1}$ for the P3 film.

The change of electrical properties of $\mathbf{P 4}$ film under stress was evaluated using a transfer process as illustrated in Fig. 9a. The $\mathbf{P 4}$ film was firstly spin coated onto a PDMS substrate, followed by straining to a certain elongation. Then the film was transferred to a silicon substrate with pre-defined source and drain electrodes in the tensile state. Fig. $9 \mathrm{~b}$ shows the change of mobility as a function of strain. The on-current slowly decreased up to an elongation of $20 \%$. After that, a considerable decrease was observed for the elongation range from $40 \%$ to $60 \%$. Though the mobility monotonously decreased as the elongation increased, the film with $60 \%$ elongation still showed field-effect performance and the mobility was $10 \%$ of the film without any strain. Fig. 9d shows the change in transfer curves measured in a stretch cycle at a strain of $40 \%$. When the P4 sample was stretched to $40 \%$ and released to $0 \%$, the on-current irreversibly decreased to about $50 \%$ of the pristine state. This decrease may be caused by the non-optimized phase structure of the films. Further study will be conducted to improve this aspect. (a)

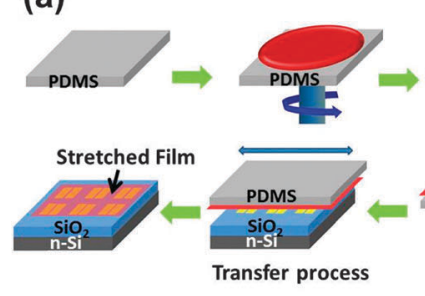

(c)

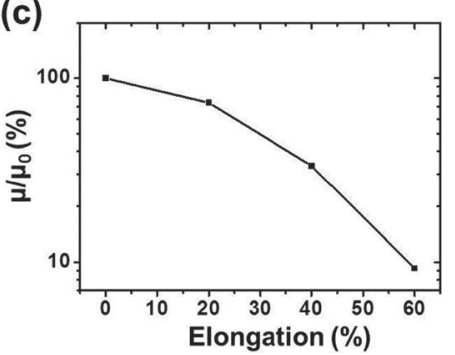

(b)

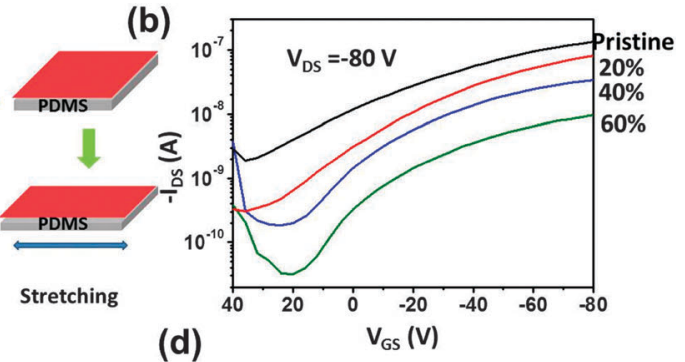

$$
\text { (d) }
$$

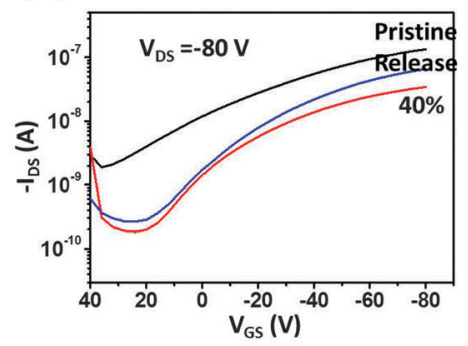

Fig. 9 (a) Schematic illustration of the steps used to measure the mobility under stress. (b) Change of the transfer curves at different strains. (c) The corresponding change of mobility as a function of strain. (d) Change of the transfer curves during a stretching cycle at a strain of $40 \%$. 


\section{Conclusions}

In conclusion, novel copolymers based on amorphous PMA blocks and two crystalline P3HT blocks were successfully synthesized via coupling of the alkyne-terminated P3HT with the diazide-terminated PMA using a click reaction. These triblock copolymers behaved as thermoplastic elastomers with a Young's modulus $(E)$ of $6 \mathrm{MPa}$ for an elongation at break of $140 \%$. The spin-cast triblock copolymer films were found to self-assemble into well ordered nanofibrillar structures under thermal annealing, which is optimal for charge transfer in fieldeffect transistors. A maximum saturated hole mobility of $9 \times$ $10^{-4} \mathrm{~cm}^{2} \mathrm{~V}^{-1} \mathrm{~s}^{-1}$ was obtained for P3HT- $b$-PMA- $b$-P3HT triblock copolymer containing $55 \mathrm{wt} \%$ P3HT. The semiconductorrubber-semiconductor (SRS) structure would have a significant impact on the next generation of stretchable electronics.

\section{Acknowledgements}

This research was supported by National Basic Research Program of China (Grant No. 2012CB723406), National Natural Science Foundation of China (Grant No. 61107014, 51203039, 21204017, 21174036, 51103034), Program for New Century Excellent Talents in University (Grant No. NCET-12-0839).

\section{Notes and references}

1 J. B. You, L. T. Dou, K. Yoshimura, T. Kato, K. Ohya, T. Moriarty, K. Emery, C. C. Chen, J. Gao, G. Li and Y. Yang, Nat. Commun., 2013, 4, 1446.

2 H. X. Zhou, L. Q. Yang and W. You, Macromolecules, 2012, 45, 607.

3 H. L. Yip and A. K. Y. Jen, Energy Environ. Sci., 2012, 5, 5994. 4 J. W. Chen and Y. Cao, Acc. Chem. Res., 2009, 42, 1709.

5 M. C. Gather, A. Kohnen and K. Meerholz, Adv. Mater., 2011, 23, 233.

6 S. Reineke, F. Lindner, G. Schwartz, N. Seidler, K. Walzer, B. Lussem and K. Leo, Nature, 2009, 459, 234.

7 T. Lei, J.-H. Dou, X.-Y. Cao, J.-Y. Wang and J. Pei, J. Am. Chem. Soc., 2013, 135, 12168.

8 P. Sonar, T. R. B. Foong, S. P. Singh, Y. Li and A. Dodabalapur, Chem. Commun., 2012, 48, 8383.

9 J. Li, Y. Zhao, H. S. Tan, Y. Guo, C.-A. Di, G. Yu, Y. Liu, M. Lin, S. H. Lim, Y. Zhou, H. Su and B. S. Ong, Sci. Rep., 2012, 2, 754.

10 M. Kaltenbrunner, T. Sekitani, J. Reeder, T. Yokota, K. Kuribara, T. Tokuhara, M. Drack, R. Schwodiauer, I. Graz, S. BauerGogonea, S. Bauer and T. Someya, Nature, 2013, 499, 458.

11 G. H. Gelinck, H. E. A. Huitema, E. Van Veenendaal, E. Cantatore, L. Schrijnemakers, J. Van der Putten, T. C. T. Geuns, M. Beenhakkers, J. B. Giesbers, B. H. Huisman, E. J. Meijer, E. M. Benito, F. J. Touwslager, A. W. Marsman, B. J. E. Van Rens and D. M. De Leeuw, Nat. Mater., 2004, 3, 106.

12 B. O'Connor, E. P. Chan, C. Chan, B. R. Conrad, L. J. Richter, R. J. Kline, M. Heeney, I. McCulloch, C. L. Soles and D. M. DeLongchamp, ACS Nano, 2010, 4, 7538.
13 A. Chortos, J. Lim, J. W. F. To, M. Vosgueritchian, T. J. Dusseault, T.-H. Kim, S. Hwang and Z. Bao, Adv. Mater., 2014, 26, 4253.

14 D. J. Lipomi, M. Vosgueritchian, B. C. K. Tee, S. L. Hellstrom, J. A. Lee, C. H. Fox and Z. N. Bao, Nat. Nanotechnol., 2011, 6, 788.

15 T. Sekitani, H. Nakajima, H. Maeda, T. Fukushima, T. Aida, K. Hata and T. Someya, Nat. Mater., 2009, 8, 494.

16 D. Y. Khang, H. Q. Jiang, Y. Huang and J. A. Rogers, Science, 2006, 311, 208.

17 D. J. Lipomi, H. Chong, M. Vosgueritchian, J. Mei and Z. Bao, Sol. Energy Mater. Sol. Cells, 2012, 107, 355.

18 S. Savagatrup, A. S. Makaram, D. J. Burke and D. J. Lipomi, Adv. Funct. Mater., 2014, 24, 1169.

19 A. D. Printz, S. Savagatrup, D. J. Burke, T. N. Purdy and D. J. Lipomi, RSC Adv., 2014, 4, 13635.

20 M. Urien, H. Erothu, E. Cloutet, R. C. Hiorns, L. Vignau and H. Cramail, Macromolecules, 2008, 41, 7033.

21 C. Muller, S. Goffri, D. W. Breiby, J. W. Andreasen, H. D. Chanzy, R. A. J. Janssen, M. M. Nielsen, C. P. Radano, H. Sirringhaus, P. Smith and N. Stingelin-Stutzmann, Adv. Funct. Mater., 2007, 17, 2674.

22 R. Duan, L. Ye, X. Guo, Y. Huang, P. Wang, S. Zhang, J. Zhang, L. Huo and J. Hou, Macromolecules, 2012, 45, 3032.

23 Z. Q. Wu, R. J. Ono, Z. Chen and C. W. Bielawski, J. Am. Chem. Soc., 2010, 132, 14000.

24 H. C. Moon, A. Anthonysamy, Y. Lee and J. K. Kim, Macromolecules, 2010, 43, 1747.

25 Q. Zhang, A. Cirpan, T. P. Russell and T. Emrick, Macromolecules, 2009, 42, 1079.

26 S. P. Wu, L. J. Bu, L. Huang, X. H. Yu, Y. C. Han, Y. H. Geng and F. S. Wang, Polymer, 2009, 50, 6245.

27 C.-A. Dai, W.-C. Yen, Y.-H. Lee, C.-C. Ho and W.-F. Su, J. Am. Chem. Soc., 2007, 129, 11036.

28 J. Liu, E. Sheina, T. Kowalewski and R. D. McCullough, Angew. Chem., Int. Ed., 2002, 41, 329.

29 M. C. Stefan, M. P. Bhatt, P. Sista and H. D. Magurudeniya, Polym. Chem., 2012, 3, 1693.

30 M. C. Iovu, M. Jeffries-El, E. E. Sheina, J. R. Cooper and R. D. McCullough, Polymer, 2005, 46, 8582.

31 M. Sommer, A. S. Lang and M. Thelakkat, Angew. Chem., Int. Ed., 2008, 47, 7901.

32 K. Palaniappan, N. Hundt, P. Sista, H. Nguyen, J. Hao, M. P. Bhatt, Y. Y. Han, E. A. Schmiedel, E. E. Sheina and M. C. Biewer, J. Polym. Sci., Part A: Polym. Chem., 2011, 49, 1802.

33 L. Z. Qiu, X. Wang, W. H. Lee, J. A. Lim, J. S. Kim, D. Kwak and K. Cho, Chem. Mater., 2009, 21, 4380.

34 G. H. Lu, H. W. Tang, Y. P. Qu, L. G. Li and X. N. Yang, Macromolecules, 2007, 40, 6579.

35 Z. Li, R. J. Ono, Z.-Q. Wu and C. W. Bielawski, Chem. Commun., 2011, 47, 197.

36 R. H. Lohwasser and M. Thelakkat, Macromolecules, 2012, 45, 3070 .

37 R. J. Kline, M. D. McGehee, E. N. Kadnikova, J. S. Liu, J. M. J. Frechet and M. F. Toney, Macromolecules, 2005, 38, 3312 . 
38 J. Jaczewska, I. Raptis, A. Budkowski, D. Goustouridis, J. Raczkowska, A. Sanopoulou, E. Pamula, A. Bernasik and J. Rysz, Synth. Met., 2007, 157, 726.

39 J. E. Mark, Physical Properties of Polymer Handbook, Springer, New York, 2nd edn, 2007.

40 Polymer Handbook, ed. I. Brandrup, E. H. Immergut and E. A. Grulke, John Wiley \& Sons, New York, 4th edn, 1999.
41 H. C. Yang, T. J. Shin, L. Yang, K. Cho, C. Y. Ryu and Z. N. Bao, Adv. Funct. Mater., 2005, 15, 671.

42 S. Savagatrup, E. Chan, S. M. Renteria-Garcia, A. D. Printz, A. V. Zaretski, T. F. O'Connor, D. Rodriquez, E. Valle and D. J. Lipomi, Adv. Funct. Mater., 2015, 25, 427.

43 X. Yu, K. Xiao, J. H. Chen, N. V. Lavrik, K. L. Hong, B. G. Sumpter and D. B. Geohegan, ACS Nano, 2011, 5, 3559. 